\title{
STRUCTURAL CHANGES DURING TRANSMITTER RELEASE AT SYNAPSES IN THE FROG SYMPATHETIC GANGLION ${ }^{1}$
}

\author{
AVERY DICKINSON-NELSON* $\neq^{2}$ AND THOMAS S. REESE*
}

\author{
* Laboratory of Neuropathology and Neuroanatomical Sciences, National Institute of Neurological and Communicative \\ Disorders and Stroke and + Laboratory of Vision Research, National Eye Institute, National Institutes of Health, Bethesda, \\ Maryland 20205
}

Received June 11, 1981; Revised July 26, 1982; Accepted July 27, 1982

\begin{abstract}
Interactions between synaptic vesicles and the presynaptic membrane which accompany transmitter release were examined at excitatory, cholinergic synapses in bullfrog sympathetic ganglia. Ganglia were fixed at rest or during electrical stimulation of the preganglionic axons and then were either thin-sectioned or freeze-fractured. Release of transmitter for brief periods is accompanied by selective depletion of four-fifths of the synaptic vesicles aligned at active zones, an overall loss of half of the synaptic vesicles in the terminals, and synaptic vesicle openings at active zones. These findings are consistent with the hypotheses that synaptic vesicles which are ready to be released are aligned at active zones and that these vesicles fuse with and add their membrane to the presynaptic membrane as they release transmitter. Larger vesicles with dense cores also contact and open onto the presynaptic membrane at the active zone, appearing to release their contents by exocytosis. The arrangement of intramembrane particles at fractured postsynaptic specializations resembles that at other excitatory, cholinergic synapses.
\end{abstract}

The structural concomitants of transmitter release are particularly well documented at neuromuscular junctions (Ceccarelli et al., 1972, 1973; Heuser and Reese, 1973, 1979, 1981; Peper et al., 1974; Heuser et al., 1974, 1979). We wanted to characterize the structural changes accompanying transmitter release at interneuronal synapses for which physiological conditions could be as well defined and chose those in the 9th or 10th sympathetic ganglion of the bullfrog, Rana catesbiana. The preganglionic fibers innervating anuran sympathetic ganglion cells release acetylcholine in the form of quanta, giving rise to fast excitatory postsynaptic potentials (EPSPs) antagonized by nicotinic blocking agents (Blackman et al., 1963a, b).

Preliminary experiments using horseradish peroxidase (Dickinson and Reese, 1973) indicated that synaptic vesicle membrane is recovered from the axolemma by coated vesicles at the frog sympathetic ganglion in a manner similar to that at the neuromuscular junction (Heuser and Reese, 1973). In order to determine whether synaptic

\footnotetext{
${ }^{1}$ This research was supported in part by a postdoctoral fellowship to A. D.-N. from the National Institutes of Health. We thank Karen Pettigrew for advice on statistical tests and Drs. Ralph Nelson and A. J. Coulombre for discussions.

${ }^{2}$ Present address: Laboratory of Vision Research, National Eye Institute, National Institutes of Health, Bethesda, MD 20205.
}

vesicle membrane is actually added to the axolemma of these synapses during transmitter release, we decided to examine the interactions between synaptic vesicles and the presynaptic membrane that accompany transmitter release, using thin sections and freeze-fracture replicas of ganglia fixed at rest or during electrical stimulation. Preliminary reports of these findings have appeared (Dickinson and Reese, 1974a, b).

\section{Materials and Methods}

Chains of sympathetic ganglia from the bullfrog Rana catesbiana were cleaned of connective tissue, mounted on stimulating and recording electrodes with a few drops of $\mathrm{Ca}^{2+}$ or $\mathrm{Mg}^{2+}$ Ringer's solution, and submerged in mineral oil. The sympathetic trunk anterior to the 9th and 10th ganglia (as identified by Ecker and Wiedersheim, 1899) was stimulated at $10 \mathrm{~Hz}$ with a voltage in excess of that required to elicit maximal $B$ and $C$ components in the compound action potential of the postsynaptic nerve (Nishi et al., 1965; Libet et al., 1968; Tosaka et al., 1968). Several volume changes of $0.5 \%$ paraformaldehyde and $0.75 \%$ glutaraldehyde in either $\mathrm{Ca}^{2+}$ or $\mathrm{Mg}^{2+}$ Ringer's solution, $\mathrm{pH} 7.3$, were added to the small bubble of Ringer's solution surrounding the 9th or 10th ganglion while resting or within $10 \mathrm{sec}$ of starting the stimulation $\left(\mathrm{Ca}^{2+}\right.$ Ringer's solution: $116 \mathrm{~mm} \mathrm{NaCl}, 2 \mathrm{~mm}$ $\mathrm{KCl}, 1.8 \mathrm{mM} \mathrm{CaCl}_{2}, 3 \mathrm{~mm}$ glucose; $\mathrm{Mg}^{2+}$ Ringer's solution: 

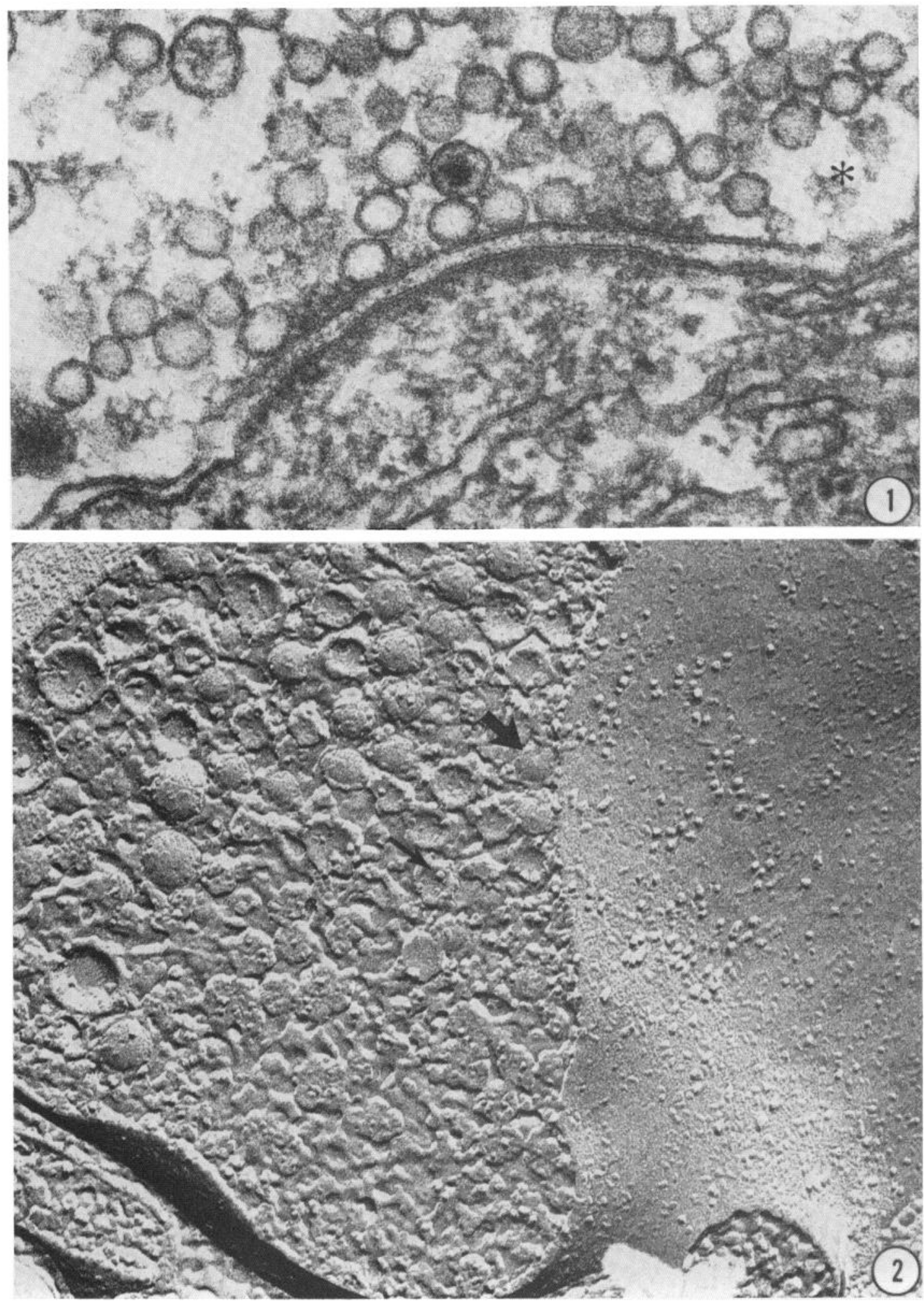

Figure 1. Thin section of a typical synapse from a resting ganglion. Synaptic vesicles approximately $50 \mathrm{~nm}$ in diameter are clustered along a smooth presynaptic membrane adjacent to patches of filamentous density. This region of presynaptic membrane with associated density and synaptic vesicles, the presynaptic specialization, is apposed to a zone of postsynaptic membrane with associated density, the postsynaptic specialization, of the ganglion cell. In regions of the terminal peripheral to the presynaptic specialization, synaptic vesicles are not aligned at the axolemma and filamentous coat material (*) appears free in the axoplasm. A few larger vesicles containing dense cores are seen in the terminal. Magnification $\times 135,000$.

Figure 2. A fracture through a resting axon terminal exposing axoplasm and the cytoplasmic half of the presynaptic membrane. The presynaptic specialization of resting synapses is characterized by arrays of large particles within a gently curving, smooth region of axolemma. Where axoplasm underlying the synaptic region has been cross-fractured, synaptic vesicles are revealed (large arrow) directly under particle-free areas of the presynaptic membrane adjacent to arrays of large particles. Large particles can be seen on the cytoplasmic half of the membrane of many of the synaptic vesicles (small arrow). Magnification $\times 135,000$. 
$108 \mathrm{~mm} \mathrm{NaCl}, 1.86 \mathrm{~mm} \mathrm{KCl}, 10 \mathrm{~mm} \mathrm{MgCl}_{2}, 3 \mathrm{~mm}$ glucose). Ganglia then were fixed further with $3 \%$ glutaraldehyde in $70 \mathrm{~mm}$ sodium cacodylate buffer containing $10 \mathrm{~mm}$ $\mathrm{Ca}^{2+}$ or $20 \mathrm{~mm} \mathrm{Mg}^{2+}$, pH 7.3 at $5^{\circ} \mathrm{C}$.

For thin sections, ganglia were fixed overnight, postfixed in $\mathrm{OsO}_{4}$, stained in uranyl acetate $(1 \%$ in $50 \mathrm{~mm}$ acetate buffer, $\mathrm{pH} 5.2,12$ to $16 \mathrm{hr}$ at $5^{\circ} \mathrm{C}$ ), dehydrated in methanol, transferred to propylene oxide, and embedded in Araldite (CY212). Silver-grey thin sections were stained with uranyl acetate and lead citrate.

For freeze-fracture preparation, ganglia were fixed for $45 \mathrm{~min}$, rinsed in buffer, equilibrated with $22 \%$ glycerol in water for $2 \mathrm{hr}$ at $22^{\circ} \mathrm{C}$, and frozen in Freon 22 (monochlorodifluoromethane) cooled in liquid nitrogen. Ganglia were fractured at $-119^{\circ} \mathrm{C}$, etched for $15 \mathrm{sec}$, and replicated in a Balzers $360 \mathrm{M}$ apparatus. In the electron microscope, terminals synapsing on B cells were not distinguished from terminals synapsing on $\mathrm{C}$ cells; thus, for the purpose of this study, the presynaptic terminals were treated as a homogeneous population. Measurements from prints were made with a Hewlett-Packard model $9864 \mathrm{~A}$ digitizer connected to a model $9810 \mathrm{~A}$ calculator.

\section{Results}

\section{The axon terminal}

Rest. Synaptic regions of resting axon terminals were examined and compared in thin sections of three ganglia and in freeze-fracture replicas of five ganglia. In thinsectioned terminals (Fig. 1), synaptic vesicles approximately $50 \mathrm{~nm}$ in diameter are typically clustered along a smooth presynaptic membrane adjacent to patches of presynaptic density. This region of presynaptic membrane with its associated density and synaptic vesicles is the presynaptic specialization, and it is characteristically apposed to the postsynaptic density of the ganglion cell. Synaptic vesicles seldom contact the axolemma outside this specialized region. Terminals also contain a few larger vesicles with dense cores; occasionally, these are found at the presynaptic specialization (Fig. 8).

In fractures revealing the cytoplasmic half of the axolemma, the presynaptic specialization is characterized by arrays of large particles approximately $10 \mathrm{~nm}$ in diameter within a gently curving area comparatively free of the small particles scattered over the rest of the axolemmal surface (Figs. 2 and 3). Where the axoplasm underlying the synaptic region is cross-fractured, synaptic vesicles are uncovered directly under these particle-free areas of presynaptic membrane adjacent to arrays of large particles (Fig. 2). Synaptic vesicles are not associated closely with the axolemma outside the presynaptic specializa- tion. Large intramembrane particles, approximately 10 $\mathrm{nm}$ in diameter, are found on the cytoplasmic half of the membrane of many synaptic vesicles.

Approximately 60 fractured presynaptic specializations were examined from five ganglia fixed while resting in $\mathrm{Ca}^{2+}$ Ringer's solution. No axolemmal deformations, which might be openings of synaptic vesicles, were seen at the presynaptic specializations of these terminals. Occasionally, an axolemmal deformation outside the presynaptic specialization was found at a resting terminal (Fig. 3). We were unable to determine whether such deformations were coated pits or synaptic vesicle openings on the basis of their appearance in the fractured axolemma. In thin sections, however, coated pits represented the only well defined invaginations of the axolemma found outside the presynaptic specialization (Fig. 7).

Stimulation. In order to define the "active zone" (Couteaux and Pecot-Dechavassine, 1970) for transmitter release at this cholinergic synapse and to describe the structural changes that occur as transmitter is being released, the preganglionic axons of eight ganglia were stimulated at $10 \mathrm{~Hz}$ in $\mathrm{Ca}^{2+}$ Ringer's solution while compound action potentials of $B$ and $C$ cells were recorded from the postsynaptic nerves. Within the first 10 sec of stimulation, $\mathrm{Ca}^{2+}$ Ringer's solution containing dilute aldehydes was added to the Ringer's solution surrounding the ganglion, and stimulation was continued for twice the $2 \frac{1}{2}$ - to 3 -min period required to decrease the amplitudes of the compound action potentials to zero. The fractured presynaptic specializations show a striking change after stimulation. Deformations of the cytoplasmic half of the axolemma appear in the particle-free regions adjacent to the arrays of large particles (Fig. 4), and corresponding protuberances adjacent to particle imprints appear on its external half (Fig. 5). Since these deformations and protuberances occur in the areas of the axolemma under which synaptic vesicles are positioned in resting terminals (Fig. 2), we also examined thin sections to see what happened to these vesicles and to the axolemma during stimulation.

At the presynaptic specializations of thin-sectioned, stimulated terminals, the axolemma shows invaginations the size and shape of synaptic vesicles (Fig. 6). No longer are synaptic vesicles clustered at the axolemma; only a few synaptic vesicles are found contacting or very close to it. Axolemmal invaginations at the presynaptic specialization are separated from synaptic vesicles above them, often by spaces containing little cytoplasmic structure. In a few instances the large vesicles with dense cores, which occasionally lie near the presynaptic specialization, appeared to be fused with the axolemma (Fig.

Figures 3. The cytoplasmic half of the axolemma of a freeze-fractured, resting axon terminal. No axolemmal deformations are seen at the presynaptic specialization, where arrays of large particles lie within a gently curving area relatively free of the small particles scattered over the rest of the axolemma. Occasionally, an axolemmal deformation is found outside the presynaptic specialization. Magnification $\times 135,000$.

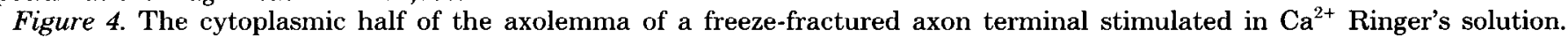
Axolemmal deformations are found adjacent to the arrays of large particles within the presynaptic specialization. Magnification $\times 135,000$.

Figure 5. The external half of the axolemma of a freeze-fractured axon terminal stimulated in $\mathrm{Ca}^{2+} \mathrm{Ringer}^{2}$ solution. Axolemmal protuberances resembling craters are found adjacent to arrays of particle imprints, apparently complementary to the large particles of the inner half of the axolemma at the presynaptic specialization. Magnification $\times 135,000$. 

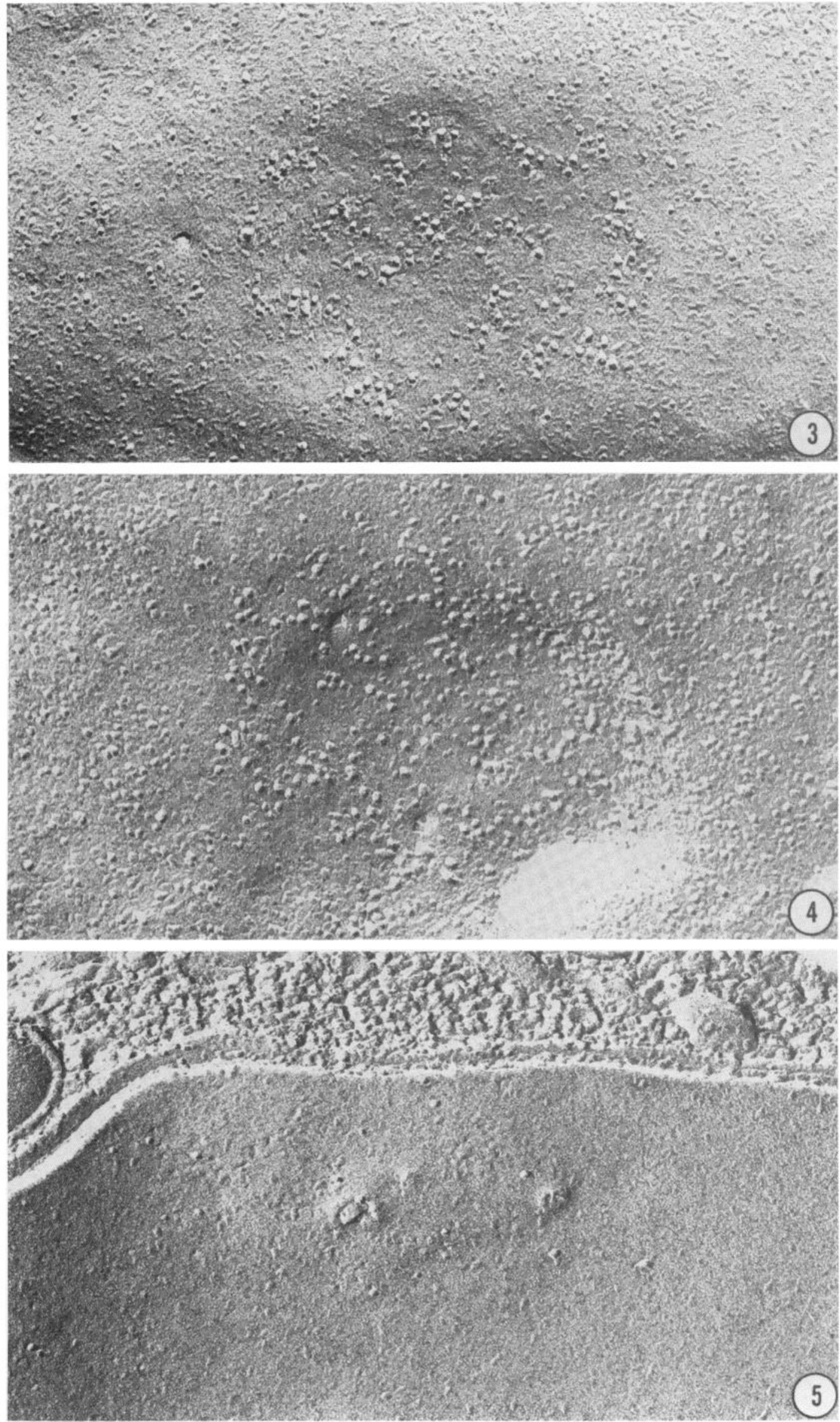
9), and in other instances electron-dense material resembling their dense cores lay under uncoated axolemmal invaginations (Fig. 9, inset). These observations suggest that the large granular vesicles also undergo exocytosis at the axolemma. One example of such exocytosis also was found at a resting synapse.

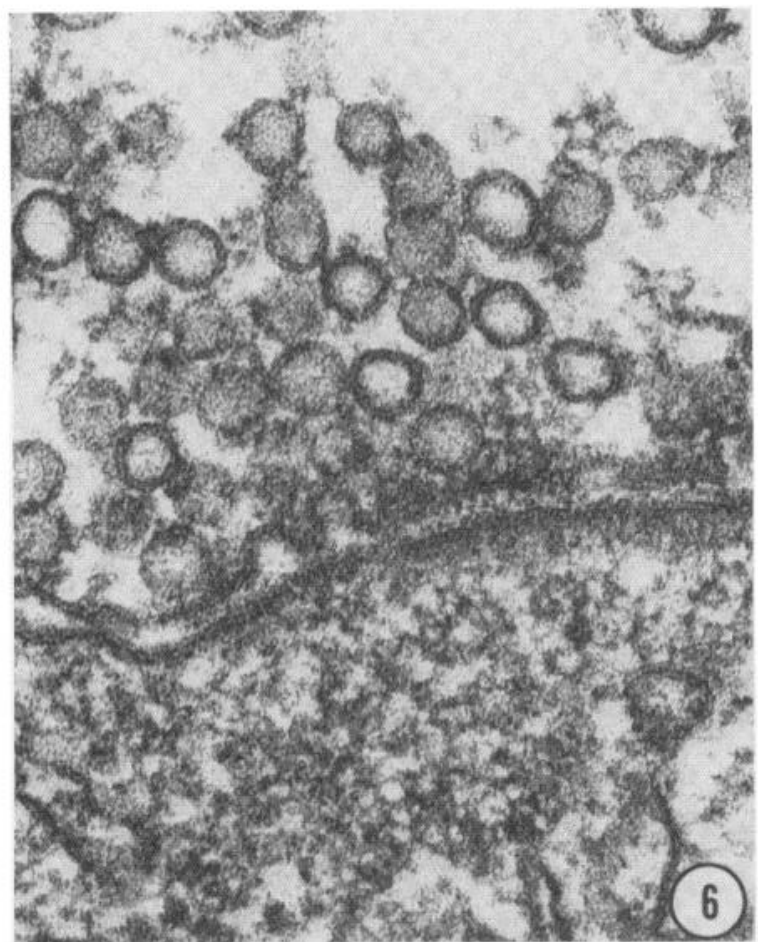

In order to determine whether the morphological changes are related to transmitter release, eight normally responding ganglia were soaked for 2 to $3 \mathrm{hr}$ in Ringer's solution containing $\mathrm{Mg}^{2+}$ instead of $\mathrm{Ca}^{2+}$. Three of these were fixed at rest. The other five were stimulated once to confirm that no postsynaptic compound action poten-

Figure 6. Thin section of a synapse from a ganglion stimulated in $\mathrm{Ca}^{2+}$ Ringer' solution. Invaginations of the axolemma are found adjacent to patches of density at the presynaptic specialization. Synaptic vesicles are further from the presynaptic membrane than at resting synapses (see Fig. 1). Invaginations are separated from surrounding synaptic vesicles. Magnification $\times 135,000$.

Figure 7. Thin section of a synapse from the same stimulated ganglion illustrated in Figure 6. A coated pit is typically the only well defined invagination of the axolemma seen outside the presynaptic specialization. A large dense core vesicle lies near the presynaptic specialization. Magnification $\times 135,000$.
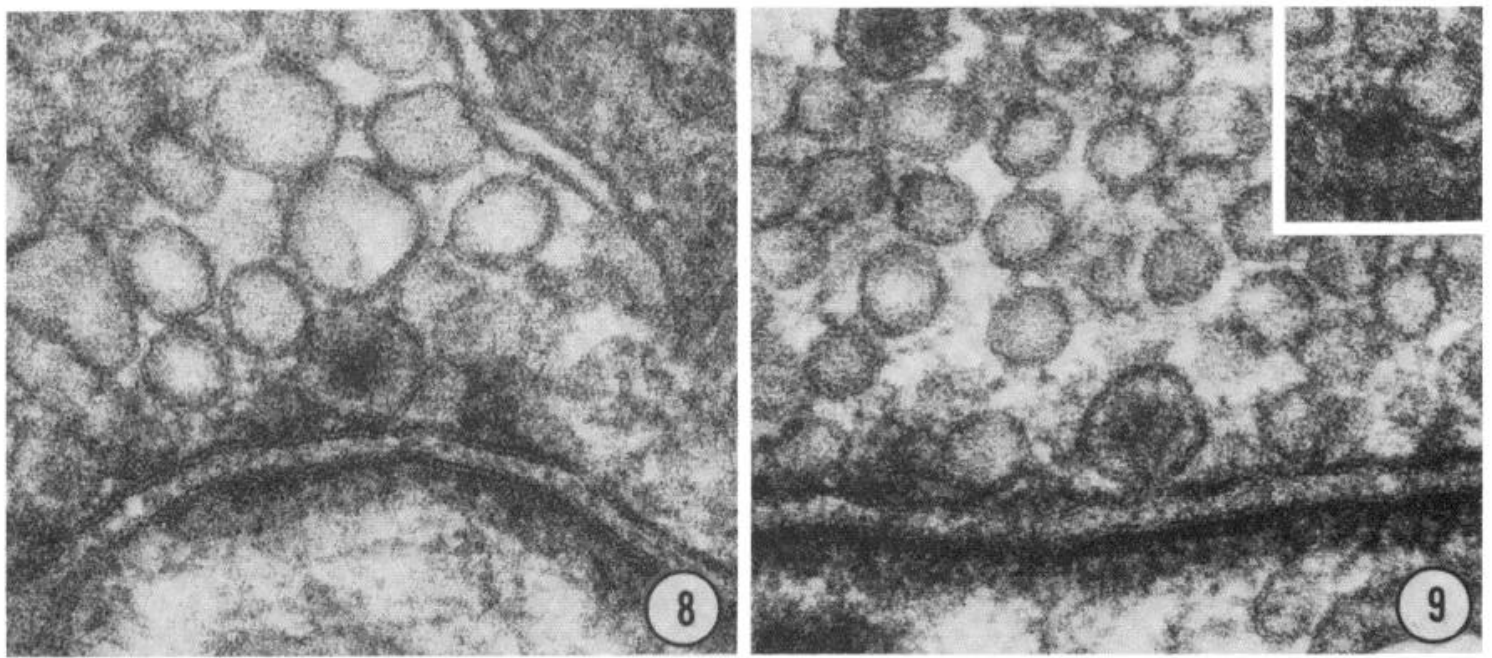

Figures 8 and 9. Large dense core vesicles at the presynaptic plasmalemma. The preparation shown in Figure 8 was stimulated for several minutes before fixing at rest, which accounts for the variability in the size of the clear synaptic vesicles. The large dense core vesicle in Figure 9 appears to be fused with the presynaptic plasmalemma. The inset in Figure 9 shows electron-dense material resembling a core under an invagination of the presynaptic plasmalemma. Magnification $\times 150,000$. 
tials appeared, and then $\mathbf{M g}^{2+}$ Ringer's solution containing dilute aldehydes was added to the ganglia while stimulation continued. Thin sections of two ganglia stimulated and fixed in this manner, showing synaptic vesicles clustered at smooth axolemmas, were indistinguishable from terminals fixed while resting in $\mathrm{Ca}^{2+}$ or $\mathrm{Mg}^{2+}$ Ringer's solution. Similarly, no axolemmal deformations were seen at any of 26 freeze-fractured presynaptic specializations in replicas from three ganglia soaked and stimulated in $\mathbf{M g}^{2+}$ Ringer's solution in the same manner; these presynaptic specializations were indistinguishable from those of terminals resting in $\mathrm{Ca}^{2+}$ or $\mathrm{Mg}^{2+}$ Ringer's solution. Hence, the invaginations of thin-sectioned axolemma, the deformations of fractured axolemma, and the loss of synaptic vesicles adjacent to the presynaptic specialization appear to depend on the release of transmitter.

These results identify an active zone at this synapse which, like that at the neuromuscular junction (Couteaux and Pecot-Dechavassine, 1970; Heuser et al., 1974), appears to correspond to the presynaptic specialization. During transmitter release, synaptic vesicles open specifically at sites within the active zone where they originally contacted the axolemma.

Quantitative aspects of exocytosis. We compared the numbers of axolemmal deformations at fractured active zones with the numbers of invaginations at thin-sectioned active zones because these numbers must agree if both structural changes are aspects of the same phenomenon. We also compared the loss of synaptic vesicles near the active zone after stimulation with losses of synaptic vesicles in other regions of the terminal because if synaptic vesicles collapse into the axolemma after they open, a selectively greater loss of vesicles near the active zone might be expected.

A carefully matched pair of 10th sympathetic ganglia from a single frog was placed in $\mathrm{Ca}^{2+}$ Ringer's solution and a similarly matched pair from another frog was placed in $\mathrm{Mg}^{2+}$ Ringer's solution. One member of each pair then was stimulated while the other was left resting. We photographed in noncontiguous thin sections the first 25 to 30 terminals which met the following criteria: (1) clearly defined presynaptic membrane apposed to a postsynaptic density at least $0.20 \mu \mathrm{m}$ long, (2) synapses with the ganglion cell body or axon hillock (axoaxonic synapses were observed but not photographed), and (3) no mitochondria within $150 \mu \mathrm{m}$ of the presynaptic specialization because they would interfere with counts of synaptic vesicles clustered near the active zone. Synaptic vesicles were counted only when their membranes were clearly defined for at least half their circumference; this criterion minimized overestimates of the numbers of synaptic vesicles which would occur when their diameter is similar to the section thickness (Heuser and Reese, 1973).

In order to determine if the numbers of deformations in fractured active zones equal the numbers of invaginations in thin-sectioned active zones, we photographed 14 active zones in replicas from three freeze-fractured ganglia that had been stimulated in $\mathrm{Ca}^{2+}$ Ringer's solution. Ten of these could be seen in their entirety and were used to estimate the mean area of stimulated active zones. The area measurements were corrected for curvature $^{3}$ using the ratio, $1: 16$, of the linear to point-topoint lengths of presynaptic specializations in thin sections. The mean area of the stimulated active zones measured in this manner was $0.24 \mu \mathrm{m}^{2}$. The clearly visible regions of the other 4 active zones also were measured and corrected for curvature. Axolemmal deformations were counted and the mean number of deformations per $\mu \mathrm{m}^{2}$ of active zone was determined to be 14.7 , or 3.5 deformations per active zone. For comparison, 27 thinsectioned terminals from a ganglion stimulated in $\mathrm{Ca}^{2+}$ Ringer's solution were examined for well defined invaginations of the axolemma at the active zones. Estimating section thickness as $60 \mathrm{~nm}$ from interference colors, 14 invaginations found in $15.0 \mu \mathrm{m}$ of thin-sectioned active zone were converted to 15.5 invaginations per $\mu \mathrm{m}^{2}$ active zone, or 3.7 invaginations per active zone, not significantly different from the measurement of deformations per active zone in replicas.

If the invaginations and deformations are formed by fusion and coalescence of synaptic vesicles with axolemma, and replacement of synaptic vesicles near the active zone is slow, the vesicles near the active zone should be depleted selectively during brief periods of stimulation. Accordingly, numbers of vesicles lying 0 to $5 \mathrm{~nm}$ (less than the thickness of a unit membrane) from the active zone axolemma before and after stimulation in $\mathrm{Ca}^{2+}$ or $\mathrm{Mg}^{2+}$ Ringer's solution were counted in thin sections. These vesicles presumably would be the first available for release upon stimulation. A mean of $82 \%$ of these "adjacent" synaptic vesicles were lost after electrical stimulation, which amounted to 3.6 vesicles per $\mu \mathrm{m}$ of thin-sectioned active zone. The numbers of adjacent vesicles per active zone section fitted a Poisson distribution, and the probability, calculated from this distribution, that the numbers of adjacent vesicles were the same at resting and stimulated active zones was less than $10^{-4}$.

An estimate of 16 adjacent vesicles per active zone resting in $\mathrm{Ca}^{2+}$ Ringer's solution was made from the number of synaptic vesicles per $\mu \mathrm{m}$ of thin-sectioned active zone, estimated section thickness, and estimated mean area of active zones. A loss of $82 \%$ of the adjacent vesicles with stimulation corresponds to a loss of 13 vesicles per active zone. The number of adjacent vesicles in terminals stimulated in $\mathrm{Mg}^{2+}$ Ringer's solution was $93 \%$ of the resting $\mathrm{Ca}^{2+}$ value, and the number of adjacent vesicles in terminals resting in $\mathbf{M g}^{2+}$ Ringer's solution was $119 \%$ of the resting $\mathrm{Ca}^{2+}$ value.

After stimulation in $\mathrm{Ca}^{2+}$ Ringer's solution, only $28 \%$ of the synaptic vesicles whose membranes lay in a second

\footnotetext{
Curvatures of active zones were determined by dividing the actual length of each presynaplic specialization by the shortest distance between its ends. At resting synapses the mean active zone curvature was $1.11 \pm 0.01$ SEM. A small significant increase in curvature occurred after stimulation, regardless of whether the axolemmal extent of invaginations was included $(1.20 \pm 0.03 \mathrm{SEM}, p>99.9 \%)$ or excluded (1.16 $\pm 0.02 \mathrm{SEM}, p>95 \%)$. Mean lengths of presynaptic specializations were not significantly different for thin-sectioned terminals from ganglia resting $(0.56 \mu \mathrm{m} \pm 0.05 \mathrm{SEM})$ or stimulated $(0.56 \mu \mathrm{m} \pm 0.04$ SEM excluding and $0.59 \mu \mathrm{m} \pm 0.03 \mathrm{SEM}$ including the axolemmal extent of invaginations) in $\mathrm{Ca}^{2+}$ Ringer's solution.
} 
TABLE I

Numbers of synaptic vesicles at varying distances from sectioned active zones Statistical tests on vesicles per $\mu \mathrm{m}$ of active zone were based on a Poisson distribution.

\begin{tabular}{|c|c|c|c|c|c|}
\hline & \multicolumn{3}{|c|}{$\begin{array}{c}\text { No. of Synaptic Vesicles } \\
\text { (per running } \mu \mathrm{m} \text { of sectioned active zone) }\end{array}$} & \multirow{2}{*}{$\begin{array}{l}\text { No. of } \\
\text { Sections }\end{array}$} & \multirow{2}{*}{$\begin{array}{c}\begin{array}{c}\text { No. of Synaptic Vesicles } \\
\text { (per } \mu \mathrm{m}^{2} \text { of terminal) }\end{array} \\
\text { All Distances } \\
\end{array}$} \\
\hline & $0-5 \mathrm{~nm}$ & $>5-55 \mathrm{~nm}$ & $>55-155 \mathrm{~nm}$ & & \\
\hline $\mathrm{Ca}^{2+}$ rest & 4.2 & 5.9 & 16.9 & 29 & 84 \\
\hline $\mathrm{Ca}^{2+}$ stimulated & $0.6^{\alpha}$ & $4.4^{b}$ & $10.9^{h}$ & 27 & $49^{a}$ \\
\hline $\mathrm{Mg}^{2+}$ rest & 5.0 & 6.6 & 19.7 & 24 & 91 \\
\hline $\mathrm{Mg}^{2+}$ stimulated & 3.9 & 6.4 & 17.3 & 29 & 83 \\
\hline
\end{tabular}

" Significant difference from $\mathrm{Ca}^{2+}$ rest $>99 \%$.

"Significant difference from $\mathrm{Ca}^{2+}$ rest $>95 \%$.

region $>5$ to $55 \mathrm{~nm}$ from the active zone were lost (1.5 vesicles per $\mu \mathrm{m}$ of thin-sectioned active zone). Tests for whether vesicles at these distances from the axolemma (the range corresponding to the diameter of a synaptic vesicle) were similar in resting and stimulated preparations rejected their similarity with $p>0.95$ for a twotailed test and $p>0.97$ for a one-tailed test. The numbers of synaptic vesicles at these distances from each active zone were estimated to be 21 at rest and 15 with stimulation. After stimulation in $\mathbf{M g}^{2+}$ Ringer's solution, the mean number of these vesicles was $108 \%$ of the resting $\mathrm{Ca}^{2+}$ value, and the number of vesicles in this region at terminals resting in $\mathrm{Mg}^{2+}$ Ringer's solution was $112 \%$ of the resting $\mathrm{Ca}^{2+}$ value.

Losses from deeper, third and fourth regions of synaptic vesicles lying $>55$ to $105 \mathrm{~nm}$ and $>105$ to $155 \mathrm{~nm}$ from the active zone were $35 \%$ after stimulation in $\mathrm{Ca}^{2+}$ Ringer's solution. An average of 29 synaptic vesicles at the $>55$ - to $105-\mathrm{nm}$ distance were present at resting active zones and 22 were present at stimulated active zones. Thirty six synaptic vesicles were present at $>105$ to $155 \mathrm{~nm}$ from resting active zones and 20 were present at this distance from stimulated active zones. The combined numbers of vesicles from these two groups in terminals stimulated in $\mathrm{Mg}^{2+}$ Ringer's solution were $102 \%$ of the resting $\mathrm{Ca}^{2+}$ values, while the numbers of these vesicles in terminals resting in $\mathrm{Mg}^{2+}$ Ringer's solution were $117 \%$ of the resting $\mathrm{Ca}^{2+}$ values. The numbers of synaptic vesicles per $\mu \mathrm{m}$ of sectioned active zone at varying distances from the axolemma in each of the four experimental groups are listed in Table I.

In order to determine the overall depletion of synaptic vesicles within the terminal, the numbers of synaptic vesicles per thin section of terminal were compared in resting and stimulated ganglia. Stimulation in $\mathrm{Ca}^{2+}$ Ringer's solution resulted in depletion to a level of $52 \%$ (74 \pm 8 SEM vesicles) of the mean of $143( \pm 17$ SEM) synaptic vesicles per thin section of resting terminal.
Numbers of synaptic vesicles in terminals stimulated or resting in $\mathrm{Mg}^{2+}$ Ringer's solution were similar to those obtained for terminals resting in $\mathrm{Ca}^{2+}$ Ringer's solution (106\% and $103 \%$, respectively). When calculated as vesicles per $\mu \mathrm{m}^{2}$ of sectioned terminal, stimulation in $\mathrm{Ca}^{2+}$ Ringer's solution resulted in a drop in vesicles to $58 \%(49$ \pm 4 SEM vesicles) of the mean of 84 ( \pm 4 SEM) vesicles per $\mu \mathrm{m}^{2}$ at rest. Values for terminals stimulated or resting in $\mathrm{Mg}^{2+}$ Ringer's solution were $99 \%$ and $108 \%$ of the resting $\mathrm{Ca}^{2+}$ values. In terminals which lose half of their synaptic vesicles overall with stimulation, an $82 \%$ loss at the active zone is a highly selective loss.

\section{Membrane specializations of the ganglion cell}

Aggregates of large particles, 8 to $10 \mathrm{~nm}$ in diameter, on the cytoplasmic half of the fractured plasma membranes of ganglion cells are associated with postsynaptic specializations (Fig. 10) or with subsurface cisterns, specialized areas of apposition between the endoplasmic reticulum and plasma membrane (Fig. 10, inset). Clusters of particle imprints (Fig. 11) were found on the external half of ganglion cell plasma membranes adjacent to active zones of axon terminals and to fractured subsurface cisterns. Particles associated with postsynaptic specializations tended to be found in round to oval clusters on outward bulges of membrane, while particles associated with subsurface cisterns tended to lie on relatively flat areas of membrane in clusters which were sometimes more elongated than the clusters of postsynaptic particles. Individual particles associated with these two types of structures were indistinguishable and their concentrations were similar, approximately 2000 per $\mu \mathrm{m}^{2}$ of aggregate. Therefore, their identification depended primarily on information from cross-fractures which exposed either an active zone or a subsurface cistern directly apposed to the specialization. No differences in particles or aggregates could be distinguished between stimulated and resting states.

Figure 10. A freeze-fractured, stimulated synapse, showing a cluster of large particles on the cytoplasmic half of the gently bulging, postsynaptic membrane above the cross-fractured axon terminal. Particle imprints may be seen on the external half of the axolemma at the active zone. Synaptic vesicles are not aligned at this stimulated active zone. The inset shows particles on the cytoplasmic half of the ganglion cell membrane directly over a subsurface cistern. Magnification $\times 120,000$.

Figure 11. Fractured, adjacent synapses revealing, on the right, presynaptic particle aggregates on the inner half of the axolemma and, on the left, an array of particle imprints on the external half of the ganglion cell membrane, apparently complementary to the postsynaptic particles characteristic of the cytoplasmic half of the ganglion cell membrane. Magnification $\times 120,000$. 

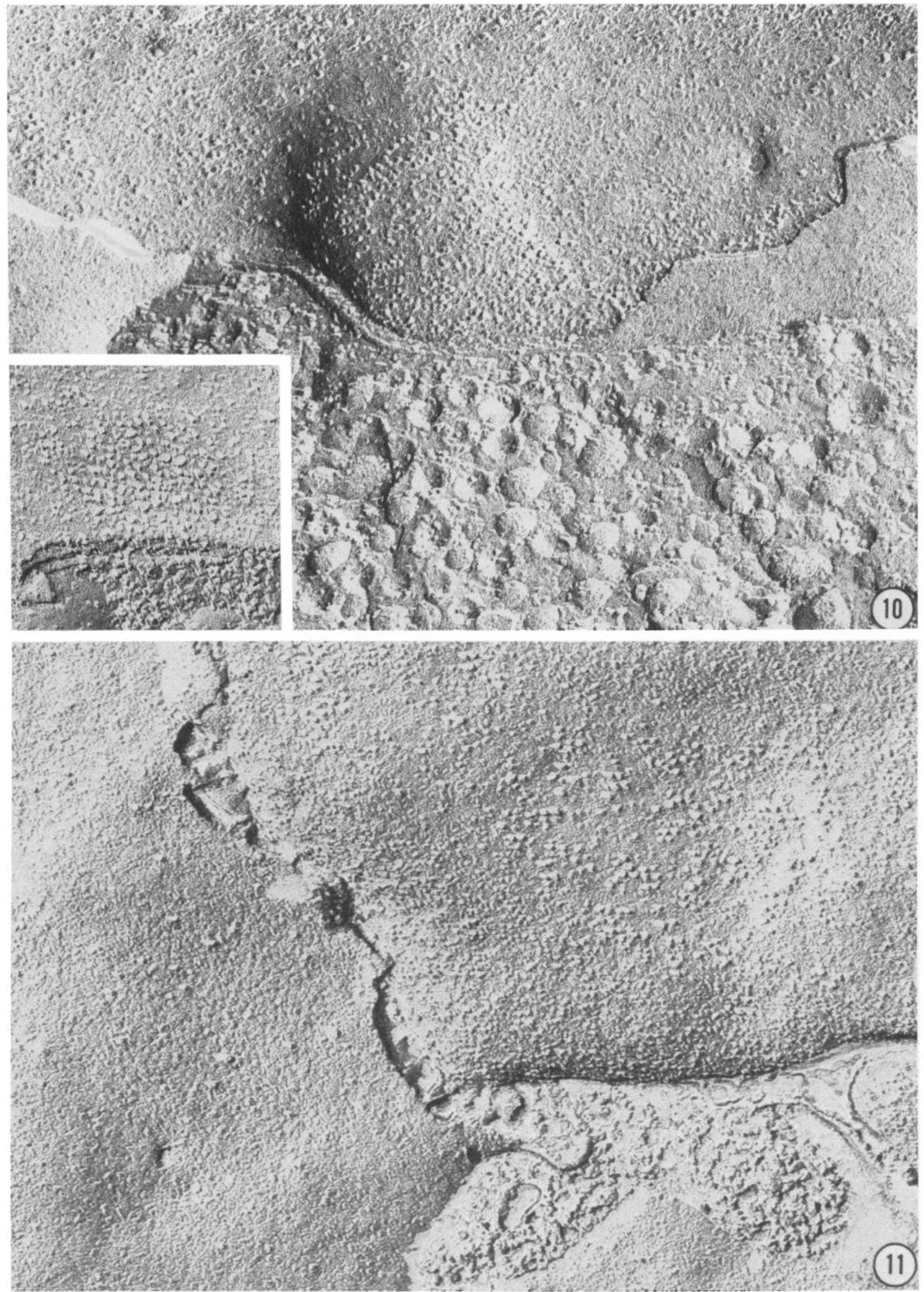
Subsurface cisterns were found beneath areas of ganglion cell plasma membrane apposed to Schwann cells or to regions of axon terminals peripheral to active zones (Watanabe and Burnstock, 1976). These subsurface cisterns do not differ in structure from those in other neurons (Henkart et al., 1976; Gulley and Reese, 1977; Gulley et al., 1978), but their frequent proximity to synapses is unusual and suggests a functional role.

\section{Discussion}

Release of transmitter evoked from excitatory, cholinergic synapses in frog sympathetic ganglion is accompanied by selective depletion of the synaptic vesicles aligned at active zones, an overall loss of half of the synaptic vesicles, and axolemmal invaginations at active zones which appear to be synaptic vesicle openings. These structural changes do not occur with nerve stimulation in the absence of transmitter release. We found no morphological evidence of vesicle release in resting synapses, which may reflect frequencies of spontaneous miniature EPSPs of less than 1/sec (Nishi et al., 1967). Moreover, the resting rate of miniature EPSPs as estimated by the numbers of vesicle openings at resting synapses apparently is not increased so sharply by aldehyde fixatives as it is at the neuromuscular junction (Smith and Reese, 1980).

Several earlier studies on muscle (Ceccarelli et al., $1972,1973)$ and on freeze-fractured central nervous system (Pfenninger et al., 1971, 1972; Akert et al., 1972; Streit et al., 1972; Pfenninger and Rovainen, 1974) included the suggestion that synaptic vesicles form openings, release their contents, and then close again. Hexagonal arrays of deformations believed to be persistent attachment sites for synaptic vesicles also are found at synapses thought to be relatively inactive, although their shapes changed during activity (Streit et al., 1972). However, the lack of significant change in the numbers of vesicle openings in these studies may have resulted from an obscuring overlay of vesicle release evoked by formaldehyde fixation (Smith and Reese, 1980).

Our studies on sympathetic ganglion yielded no evidence that deformations represent stable attachment sites for synaptic vesicles. Thin sections of terminals resting in $\mathrm{Ca}^{2+}$ or $\mathrm{Mg}^{2+}$ Ringer's solution often show vesicles in contact with the presynaptic membrane at the active zone, but corresponding freeze-fracture views reveal no axolemmal deformations there. Invaginations in the axolemma appear at the active zone after stimulation, but thin sections through comparable active zones fail to show any synaptic vesicles touching these invaginations. These findings seem more compatible with the alternative that synaptic vesicles collapse into the presynaptic membrane after fusing with it and that the rate of fusion exceeds the rate of replacement, which is therefore a rate-limiting step in sustained release (Highstein and Bennett, 1975). Several lines of direct evidence at the frog neuromuscular junction show that synaptic vesicles there collapse into the plasma membrane after they open (Heuser and Reese, 1973, 1979, 1981; von Wedel et al., 1981).

Our observation of selective depletion of vesicles immediately adjacent to the axolemma further supports the concept that synaptic vesicles fuse with and collapse into it as they release transmitter. No selective depletion of vesicles would be expected if synaptic vesicles re-formed at the active zone unless re-formed vesicles immediately moved away from it. However, this shift would result in an increase in synaptic vesicles neighboring the active zone which would be proportional to the depletion of vesicles at the active zone. Instead, there is depletion of approximately one-quarter of the vesicles neighboring the active zone; there are simply not enough neighboring vesicles to conceal a group of vesicles added by moving back from the active zone. The increase in curvature of the active zone after stimulation in sympathetic ganglion and in the brain (Streit et al., 1972) is further indirect evidence that vesicles add their membrane to the axolemma after they open.

While many studies have shown overall depletion of synaptic vesicles with stimulation (e.g., Parducz et al., 1971; Clark et al., 1972; Pysh and Wiley, 1972, 1974; Perri et al., 1972; Heuser and Reese, 1973; Birks, 1974), widely varying effects of stimulation have also been reported (e.g., de Robertis and Vas Ferreira, 1957; Green, 1966; Parducz and Feher, 1970). Counts of vesicles close to the synaptic cleft have shown modest depletions (Hubbard and Kwanbunbumpen, 1968; Perri et al., 1972), no change (Korneliussen, 1972), or even increases that were regarded as vesicle mobilization (Jones and Kwanbunbumpen, 1970; Quilliam and Tamarind, 1973). Several studies report a greater proportion of the total vesicle population located near the synaptic cleft after stimulation (Csillik and Bense, 1971; Perri et al., 1972; Korneliussen, 1972; Model et al., 1975). Even the studies which singled out vesicles at the active zone failed to demonstrate a marked, selective depletion, possibly because fixative was applied after, rather than during stimulation, allowing time for other vesicles to move up to the active zone. It is also possible that the osmium fixation used in some studies increased the rate of transmitter release sufficiently to obscure differences between resting and stimulated active zones (Perri et al., 1972; Heuser and Reese, 1974).

The content of the large vesicles with dense cores is unknown. It is of interest, however, that a peptide resembling luteinizing hormone-releasing hormone (LHRH) is a transmitter in the sympathetic ganglion responsible for a late slow EPSP (Jan et al., 1979, 1980a; Nishi and Koketsu, 1968) and has been localized primarily to synaptic boutons on $\mathrm{C}$ cells (Jan et al., 1980b). Since the large dense core vesicles contact and open onto the presynaptic membrane, they could release a noncholinergic transmitter such as the LHRH-like peptide. In fact, the number of large dense core vesicles in motor nerve terminals decreases during nerve stimulation (Lynch, 1980). Our sampling process did not allow us to determine whether large dense core vesicles are mixed with $50-\mathrm{nm}$ vesicles in terminals on all ganglion cells.

The aggregates of 8- to 10-nm particles which fracture predominantly with the cytoplasmic half of the postsynaptic membrane in frog sympathetic ganglion are characteristic also of postsynaptic specializations at frog and mammalian neuromuscular junctions (Heuser et al., 1974; Peper et al., 1974; Rash and Ellisman, 1974) and Torpedo and Electrophorus electroplaques (Cartaud et al., 1973; Rosenbluth, 1975). Although in frog sympa- 
thetic ganglion no direct evidence exists for the identity of the particles on fractured postsynaptic membranes, peroxidase-labeled $\alpha$-bungarotoxin and anti-acetylcholine receptor antibodies have been shown to bind exclusively within the synaptic cleft at the postsynaptic specialization (Marshall, 1981), where the particles are found, and it is likely that they represent locations of cholinergic receptors. In electroplaques it is clear that the particles are loci of cholinergic receptors (Cartaud et al., 1973; Michaelson et al., 1976; Rash el al., 1978; Heuser and Salpeter, 1979), and at neuromuscular junctions, labeled $\alpha$-bungarotoxin has been localized at postsynaptic specializations (Daniels and Vogel, 1975; Fertuck and Salpeter, 1974, 1976; Matthews-Bellinger and Salpeter, 1978)).

The active zone at the synapses studied here may be regarded as a cell surface specialization which holds secretory vesicles in readiness and directs their secretory product toward these postsynaptic receptors. This function may depend on the cytoplasmic filamentous material and grouping of large intramembrane particles, which are thought to be calcium channels (Pumplin et al., 1981), coupled with some means of mobilizing vesicles from deeper within the synapse (Smith et al., 1970; Gulley and Reese, 1981). The active zone differentiates synapses from other secretory cells. For instance, no vesicles contact the plasmalemma of unstimulated Limulus amebocytes which normally release their secretory granules over their entire surface. Contact between secretory granules and the plasmalemma in amebocytes and many other secretory cells occurs only after secretion is triggered (Ornberg and Reese, 1981). The secretory granules in amebocytes are associated with cytoplasmic filaments, though the nature and exact role of these filaments in initiating secretion remain to be defined. Something analogous to this filament-associated "approach step" must bring synaptic vesicles up to the active zones at frog sympathetic ganglion synapses prior to the secretory stimulus. Some of these synaptic vesicles, perhaps those actually in contact with the axolemma, then are ready to be released immediately when an action potential arrives. We assume that during repetitive stimulation, replacement of approached vesicles is slower than their release, which is why this subgroup can be depleted selectively.

\section{References}

Akert, K., K. Pfenninger, C. Sandri, and H. Moor (1972) Freezeetching and cytochemistry of vesicles and membrane complexes in synapses of the central nervous system. In Structure and Function of Synapses, G. D. Pappas and D. P. Purpura, eds., pp. 67-86, Raven Press, New York.

Birks, R. (1974) The relationship of transmitter release and storage to fine structure in a sympathetic ganglion. J. Neurocytol. 3: 133-160.

Blackman, J. G., B. L. Ginsborg, and C. Ray (1963a) Synaptic transmission in the sympathetic ganglion of the frog. $J$. Physiol. (Lond.) 167: 355-373.

Blackman, J. G., B. L. Ginsborg, and C. Ray (1963b) On the quantal release of transmitter at a sympathetic synapse. J. Physiol. (Lond.) 167: 402-415.

Cartaud, J., E. L. Benedetti, J. B. Cohen, J. C. Meunier, and J. P. Changeux (1973) Presence of a lattice structure in membrane fragments rich in nicotinic receptor protein from the electric organ of Torpedo marmorata. FEBS Lett. 33: 109-
113.

Ceccarelli, B., W. P. Hurlbut, and A. Mauro (1972) Depletion of vesicles from frog neuromuscular junctions by prolonged tetanic stimulation. J Cell Biol. 54: 30-38.

Ceccarelli, B., W. P. Hurlbut, and A. Mauro (1973) Turnover of transmitter and synaptic vesicles at the frog neuromuscular junction. J. Cell Biol. 57: 499-524.

Clark, A. W., W. P. Hurlbut, and A. Mauro (1972) Changes in the fine structure of the neuromuscular junction of the frog caused by black widow spider venom. J. Cell Biol. 52: 1-14.

Couteaux, M. R., and M. Pecot-Dechavassine (1970) Vesicules synaptiques et poches au niveau des "zones actives" de la junction neuromusculaire. C. R. Acad. Sci. (D) (Paris) 271: 2346-2349.

Csillik, B., and B. Bense (1971) Function dependent alterations in the distribution of synaptic vesicles. Acta Biol. Acad. Sci. Hung. 22: 131-139.

Daniels, M. P., and Z. Vogel (1975) Immunoperoxidase staining of $\alpha$-bungarotoxin binding sites in muscle endplates shows distribution of acetylcholine receptors. Nature 254: 339-341.

de Robertis, E. D. P., and A. Vas Ferreira (1957) Submicroscopic changes of the nerve endings in the adrenal medulla after stimulation of the splanchnic nerve. J. Biophys. Biochem. Cytol. 3: 611-614.

Dickinson, A. H., and T. S. Reese (1973) Morphological changes after electrical stimulation of frog sympathetic ganglia. Anat. Rec. 175: 306.

Dickinson, A. H., and T. S. Reese (1974a) Freeze-fractured synapses in stimulated and unstimulated frog sympathetic ganglia. Anat. Rec. 178: 344-345.

Dickinson, A. H., and T. S. Reese (1974b) Interactions of synaptic vesicles with the plasmalemma in frog sympathetic ganglia. J. Cell Biol. 63: 83a.

Ecker, A., and R. Wiedersheim (1899) Anatomie des Frosches, Vol. 2, Ed. 3, revised by E. Gaupp, p. 212, Braunschweig, Vieweg.

Fertuck, H. C., and M. M. Salpeter (1974) Localization of acetylcholine receptor by ${ }^{125} \mathrm{I}$ labeled $\alpha$-bungarotoxin binding at mouse motor endplates. Proc. Natl. Acad. Sci. U. S. A. 71: 1376-1378.

Fertuck, H. C., and M. M. Salpeter (1976) Quantitation of junctional and extrajunctional acetylcholine receptors by electron microscope autoradiography after ${ }^{125} I-\alpha$-bungarotoxin binding at mouse neuromuscular junctions. J. Cell Biol. 69: 144-158.

Green, K. (1966) Electron microscopic observations on the relationship between synthesis of synaptic vesicles and acetylcholine. Anat. Rec. 154: 351.

Gulley, R. L., and T. S. Reese (1977) Freeze-fracture studies on the synapses in the organ of Corti. J. Comp. Neurol. 171: 517-544.

Gulley, R. L., and T. S. Reese (1981) Cytoskeletal organization at the postsynaptic complex. J. Cell Biol. 91: 298-302.

Gulley, R. L., D. M. D. Landis, and T. S. Reese (1978) Internal organization of membranes and end bulbs of Held in the anteroventral cochlear nucleus. J. Comp.Neurol. 180: 707742.

Henkart, M., D. M. D. Landis, and T. S. Reese (1976) Similarity of junctions between plasma membranes and endoplasmic reticulum in muscle and neurons. J. Cell Biol. 70: 338-347.

Heuser, J. E., and T. S. Reese (1973) Evidence for recycling of synaptic vesicle membrane during transmitter release at the frog neuromuscular junction. J. Cell Biol. 57: 315-344.

Heuser, J. E., and T. S. Reese (1974) Morphology of synaptic vesicle discharge and reformation at the frog neuromuscular junction. In Synaptic Transmission and Neuronal Interaction, M. V. L. Bennett, ed., pp. 59-77, Raven Press, New York.

Heuser, J. F., and T. S. Reese (1979) Synaptic-vesicle exocytosis 
captured by quick freezing. In The Neurosciences: Fourth Study Program, F. O. Schmitt and F. G. Worden, eds., pp. 573-600, MIT Press, Cambridge, MA.

Heuser, J. E., and T. S. Reese (1981) Structural changes following transmitter release at the frog neuromuscular junction. $J$. Cell Biol. 88: 564-580.

Heuser, J. E., and S. R. Salpeter (1979) Organization of acetylcholine receptors in quick-frozen, deep-etched, and rotaryreplicated Torpedo postsynaptic membrane. J. Cell Biol. 82: 150-173.

Heuser, J. E., T. S. Reese, and D. M. D. Landis (1974) Functional changes in frog neuromuscular junctions studied with freeze-fracture. J. Neurocytol. 3: 109-131.

Heuser, J. E., T. S. Reese, M. J. Dennis, Y. Jan, L. Jan, and L. Evans (1979) Synaptic vesicle exocytosis captured by quick freezing and correlated with quantal transmitter release. J. Cell Biol. 81: 275-300.

Highstein, S. M., and M. V. L. Bennett (1975) Fatigue and recovery of transmission at the Mauthner fiber-giant fiber synapse of the hatchet-fish. Brain Res. 98: 229-242.

Hubbard, J. I., and S. Kwanbunbumpen (1968) Evidence for the vesicle hypothesis. J. Physiol. (Lond.) 194: 407-420.

Jan, Y. N., L. Y. Jan, and S. W. Kuffler (1979) A peptide as a possible transmitter in sympathetic ganglia of the frog. Proc. Natl. Acad. Sci. U. S. A. 76: 1501-1505.

Jan, Y. N., L. Y. Jan, and S. W. Kuffler (1980a) Further evidence for peptidergic transmission in sympathetic ganglia. Proc. Natl. Acad. Sci. U. S. A. 77: 5008-5012.

Jan, L. Y., Y. N. Jan, and M. S. Brownfield (1980b) Peptidergic transmitters in synaptic boutons of sympathetic ganglia. Nautre 288: $380-382$.

Jones, S. F., and S. Kwanbunbumpen (1970) The effects of nerve stimulation and hemicholinium on synaptic vesicles at the mammalian neuromuscular junction. J. Physiol. (Lond.) 207: $31-50$.

Korneliussen, H. (1972) Ultrastructure of normal and stimulated motor endplates. Z. Zellforsch. 130: 28-57.

Libet, B., S. Chichibu, and T. Tosaka (1968) Slow synaptic responses and excitability in sympathetic ganglia of the bullfrog. J. Neurophysiol. 31: 383-395.

Lynch, K. (1980) Stimulation-induced reduction of large dense core vesicle numbers in cholinergic motor nerve endings. Brain Res. 194: 249-254.

Marshall, L. M. (1981) Synaptic localization of $\alpha$-bungarotoxin binding which blocks nicotinic transmission at frog sympathetic neurons. Proc. Natl. Acad. Sci. U. S. A. 78: 1948-1952.

Matthews-Bellinger, J., and M. M. Salpeter (1978) Distribution of acetylcholine receptors at frog neuromuscular junctions with a discussion of some physiological implications. J. Physiol. (Lond.) 279: 197-213.

Michaelson, D. M., J. R. Duguid, D. L. Miller, and M. A. Raftery (1976) Reconstitution of a purified acetylcholine receptor. J. Supramol. Struct. Cell. Biochem. 4: 419-425.

Model, P.G., S. M. Highstein, and M. V. L. Bennett (1975) Depletion of vesicles and fatigue of transmission at a vertebrate central synapse. Brain Res. 98: 209-228.

Nishi, S., and K. Koketsu (1968) The early and late afterdischarges of amphibian sympathetic postganglionic fibers. J. Neurophysiol. 31: 109-121.

Nishi, S., H. Soeda, and K. Koketsu (1965) Studies on sympathetic $\mathrm{B}$ and $\mathrm{C}$ neurons and patterns of preganglionic innervation. J. Cell. Comp. Physiol. 66: 19-32.

Nishi, S., H. Soeda, and K. Koketsu (1967) Release of acetylcholine from sympathetic preganglionic nerve terminals. J. Neurophysiol. 30: 114-134.

Ornberg, R. L., and T. S. Reese (1981) Beginning of exocytosis captured by rapid freezing of Limulus amebocytes. J. Cell Biol. 90: 40-54.

Parducz, A., and O. Feher (1970) Fine structural alterations of presynaptic endings in the superior cervical ganglion of the cat after exhausting preganglionic stimulation. Experientia 26: 629-630.

Parducz, A., O. Feher, and F. Joo (1971) Effects of stimulation and hemicholinium (HC3) on the fine structure of nerve endings on the superior cervical ganglion of the cat. Brain Res. 34: 61-72.

Peper, K., F. Dryer, C. Sandri, K. Akert, and H. Moor (1974) Structure and ultrastructure of the frog motor endplate: A freeze-etching study. Cell Tissue Res. 149: 437-455.

Perri, V., O. Sacchi, E. Raviola, and G. Raviola (1972) Evaluation of the number and distribution of synaptic vesicles at cholinergic nerve endings after sustained stimulation. Brain Res. 39: 526-529.

Pfenninger, K., K. Akert, H. Moor, and C. Sandri (1971) Freezeetching of presynaptic membranes in the central nervous system. Philos. Trans. R. Soc. Lond. (Biol.) 261: 387-389.

Pfenninger, K., K. Akert, H. Moor, and C. Sandri (1972) The fine structure of freeze-fractured presynaptic membranes. J. Neurocytol. 1: 129-149.

Pfenninger, K. H., and C. M. Rovainen (1974) Stimulation of calcium-dependence of vesicle attachment sites in the presynaptic membranes. A freeze-cleave study on the lamprey spinal cord. Brain Res. 72: 1-23.

Pumplin, D. W., T. S. Reese, and R. Llinas (1981) Are the presynaptic active zone particles the calcium channels? Proc. Natl. Acad. Sci. U. S. A. 78: 7210-7214.

Pysh, J. J., and R. G. Wiley (1972) Morphologic alterations of synapses in electrically stimulated superior cervical ganglia of the cat. Science 176: 191-193.

Pysh, J. J., and R. G. Wiley (1974) Synaptic vesicle depletion and recovery in cat sympathetic ganglia electrically stimulated in vivo. J. Cell Biol. 60: 365-374.

Quilliam, J. P., and D. L. Tamarind (1973) Some effects of preganglionic nerve stimulation on synaptic vesicle populations in the rat superior cervical ganglion. J. Physiol. (Lond.) 235: 317-331.

Rash, J. E., and M. H. Ellisman (1974) Studies of excitable membranes. I. Macromolecular specializations of the neuromuscular junction and the nonjunctional sarcolemma. J. Cell Biol. 63: 567-586.

Rash, J. E., C. S. Hudson, and M. H. Ellisman (1978) Ultrastructure of acetylcholine receptors at the mammalian neuromuscular junction. In Cell Membrane Receptors for Drugs and Hormones: A Multidisciplinary Approach, L. Bolis and R. W. Straub, eds., pp. 47-68, Raven Press, New York.

Rosenbluth, J. (1975) Synaptic membrane structure in Torpedo electric organ. J. Neurocytol. 4: 697-712.

Smith, D. S., U. Jarlfors, and R. Beranek (1970) The organization of synaptic axoplasm in the lamprey (Petromyzon marinus) central nervous system. J. Cell Biol. 46: 199-219.

Smith, J. E., and T. S. Reese (1980) Use of aldehyde fixatives to determine the rate of synaptic transmitter release. J. Exp. Biol. 89: 19-29.

Streit, P., K. Akert, O. Sandri, R. P. Livingston, and H. Moor (1972) Dynamic ultrastructure of presynaptic membranes at nerve terminals in the spinal cord of rats. Anesthetized and unanesthetized preparations compared. Brain Res. 48: 11-26.

Tosaka, T., S. Chichibu, and B. Libet (1968) Intracellular analysis of slow inhibitory and excitatory postsynaptic potentials in sympathetic ganglia of the frog. J. Neurophysiol. 31 : 396-409.

von Wedel, R. J., S. S. Carlson, and R. B. Kelly (1981) Transfer of synaptic vesicle antigens to the presynaptic plasma membrane during exocytosis. Proc. Natl. Acad. Sci. U. S. A. 78: 1014-1018.

Watanabe, H., and G. Burnstock (1976) Junctional subsurface organs in frog sympathetic ganglion cells. J. Neurocytol. 5: 125-136. 